\title{
Bench-to-bedside translation of magnetic nanoparticles
}

\author{
Dhirender Singh ${ }^{1,2}$, JoEllyn M McMillan², Alexander V Kabanov ${ }^{3}$, Marina Sokolsky- \\ Papkov $^{3}$, and Howard E Gendelman ${ }^{1,2, *}$ \\ ${ }^{1}$ Department of Pharmaceutical Sciences, University of Nebraska Medical Center, Omaha, NE \\ 68198-5800, USA \\ ${ }^{2}$ Department of Pharmacology \& Experimental Neuroscience, University of Nebraska Medical \\ Center, Omaha, NE 68198-5800, USA
}

${ }^{3}$ Center for Nanotechnology in Drug Delivery, UNC Eshelman School of Pharmacy, University of North Carolina at Chapel Hill, Chapel Hill, NC, USA

\begin{abstract}
Magnetic nanoparticles (MNPs) are a new and promising addition to the spectrum of biomedicines. Their promise revolves around the broad versatility and biocompatibility of the MNPs and their unique physicochemical properties. Guided by applied external magnetic fields, MNPs represent a cutting-edge tool designed to improve diagnosis and therapy of a broad range of inflammatory, infectious, genetic and degenerative diseases. Magnetic hyperthermia, targeted drug and gene delivery, cell tracking, protein bioseparation and tissue engineering are but a few applications being developed for MNPs. MNPs toxicities linked to shape, size and surface chemistry are real and must be addressed before clinical use is realized. This article presents both the promise and perils of this new nanotechnology, with an eye towards opportunity in translational medical science.
\end{abstract}

\section{Keywords}

biocompatibility; drug targeting; magnetic hyperthermia; MRI; nanoparticle; targeted drug and gene delivery; tissue engineering

\section{Background}

The potential of nanomedicine in revolutionizing how modern medicine is practiced for diagnostics and therapies is enormous [1]. Synthetic or natural polymer carriers that can encapsulate therapeutic agents or carry them adsorbed or chemically linked to the particle surface can extend therapeutic indices and improve early diagnostics [2]. Among the range of nanoparticulate systems being explored for translational medicine, magnetic nanoparticles

\footnotetext{
(C) 2014 Future Medicine Ltd

*Author for correspondence Tel.: +1 402559 8920, Fax: +1 4025593744 hegendel@ unmc.edu.

Financial \& competing interest disclosure

The authors have no other relevant affiliations or financial involvement with any organization or entity with a financial interest in or financial conflict with the subject matter or materials discussed in the manuscript apart from those disclosed.

No writing assistance was utilized in the production of this manuscript.
} 
(MNPs) have gained increasing attention due to their unique functional properties [3]. The superpara-magnetic iron oxide core of MNPs offers both imaging and targeting capabilities in the presence of a magnetic field. Therefore, MNPs coated with a biocompatible polymer and carrying drug cargo can use a magnetic field to facilitate targeted drug delivery at specific disease sites, and MRI to measure the targeting efficacy (Figure 1) [4].

Development of nanotherapeutics for treatment of microbial infections that include HIV can follow a similar approach [5].

Superparamagnetism of iron oxide particles is a prerequisite to MNP use, as well as an underlying reason for its limitations. Indeed, MNPs tend to aggregate under a magnetic field, potentially leading to cerebral and pulmonary embolism [6]. However, MNPs with improved stability, as well as reduced toxicity and immunogenicity, can be synthesized by employing biocompatible materials. Particle size should be small enough to remain in circulation while navigating successfully through capillary networks [7]. Under acidic conditions, iron is released and processed by common physiologic storage mechanisms [8]. Iron oxide MNPs have been approved as contrast agents for bioimaging by the US FDA [9]. Herein, we review the utilization of MNPs for specific clinical applications (Table 1). This includes works by our own laboratories that have recently developed small magnetite antiretroviral therapy (SMART) that can be applied as a theranostic modality, where drug and magnetite are encased in a single polymer core enabling rapid assessment of pharmacokinetic and pharmacodynamics by MRI [10].

\section{MNP systems: translational design considerations}

For successful development of drug delivery systems based on MNPs, several physicochemical characteristics, particle stability, biocompatibility and drug loading capacity of the system, as well as MNP characteristics, such as responsiveness to a magnetic field, should be taken into consideration. The physicochemical characteristics, size (hydrodynamic radius), surface charge, surface hydrophobicity and surface coating, as well as shape, guide the stability, biocompatibility and biodistribution of the drug delivery system.

While the hydrodynamic radius of the particle system impacts colloidal stability, core size of the MNP correlates with responsiveness to a magnetic field [6]. Saturation magnetization of MNPs (which governs the responsiveness to the magnetic field) is known to decrease with a decrease in particle size [11]. In addition, it is known that particles with a hydrodynamic radius $<2 \mathrm{~nm}$ damage intracellular organelles due to their filtration through cellular membranes [16]. Therefore, MNPs with hydrodynamic radius in the size range of 10-100 $\mathrm{nm}$ are considered optimal for in vivo delivery because they: are above the toxic threshold; can escape from renal clearance and elimination by the reticuloendothelial system (RES); and utilize MNPs with a core size big enough to maintain high saturation magnetization values [17]. Nanoparticle shape also impacts biodistribution and biocompatibility. Cell uptake of rod-shaped particles is greater than spherical particles for sizes $>100 \mathrm{~nm}$ [18]. This selectivity is reversed for particles $<100 \mathrm{~nm}$ in size $[18,19]$ and uptake of ligand-coated rodshaped nanoparticles can depend upon how they are presented to the cell and interact with surface receptors [20]. Other studies have demonstrated that rod-shaped and nonspherical 
PEGylated nanoparticles exhibited prolonged systemic circulation compared with spherical particles [21], in part due to decreased stimulation of phagocytic cells by rod-shaped/ nonspherical particles compared with spherical particles [21].

Surface charge/surface coating of MNPs is an additional critical component to govern biodistribution and clearance of MNPs. MNPs have an intrinsic tendency to agglomerate due to their high surface energy [22], although agglomeration can be prevented through electrostatic/steric repulsion. Notably, surface charge guides MNP uptake and interactions with the RES. Positively charged nanoparticles are taken up more rapidly by the cells when compared with negatively charged or neutral particles [23] and a hydrophobic MNP surface facilitates adsorption of plasma proteins (i.e., opsonization) and extracellular matrix, resulting in rapid RES clearance. These surface properties can be counteracted by grafting a hydrophilic layer onto the particle surface or coating them with a protective shell (a steric barrier) [7]. Furthermore, the additional coating prevents MNP surface oxidation and can provide surface chemistry for bioconjugation of targeting ligands and drugs [24]. The targeting ligands can be antibodies, peptides or proteins that possess affinity for defined target cells or tissues [25]. The strategy of 'active targeting', together with magnetic targeting, holds promise to enhance delivery of drug encapsulated in MNPs to disease sites, improving theranostic efficacy [26].

\section{Hyperthermia}

Magnetic hyperthermia is based on the concept that MNPs can generate heat using an external alternating magnetic field (AMF), and temperatures above $37{ }^{\circ} \mathrm{C}$ result in accelerated cell apoptosis/death. MNPs and magnetic fields have been employed for thermal destruction of cancerous cells [27]. Magnetic hyperthermia can be used for tumor management in conjunction with chemotherapy, radiotherapy and surgery. The specificity of this approach lies in the hypersensitivity to higher temperatures exhibited by tumor cells when compared with normal cells. Moreover, the degree of heat generation can be tailored by tuning the magnetic properties of MNPs, as well as the external magnetic field characteristics [6,28]. Based upon the extent of heat generation, MNP treatments are separated into hyperthermic effects or thermoablation. This refers to cell death (or carbonization) seen when cells are heated to $46-48{ }^{\circ} \mathrm{C}$ [6]. More specific and effective heating regimens can be achieved when magnetic hyperthermia is used with another heating source such as microwave, electromagnetic radiation [29] or ultrasound [30].

The ability of MNPs to induce hyperthermia depends on particle size. For example, maghemite particles $11.2 \mathrm{~nm}$ in size exhibited a higher heating rate at a frequency of 700 $\mathrm{kHz}$ and field amplitude of $24.5 \mathrm{kA} / \mathrm{m}$ compared with smaller nanoparticles [31]. Moreover, it has also been reported that for particles with a core size $<12 \mathrm{~nm}$, the specific absorption rate (which can be referred to as 'heating power') increases slightly with an increase in magnetic particle core size. However, for particles with a core size $>12 \mathrm{~nm}$, the increment in size can be accompanied by diminished specific absorption rate [32].

MNPs can accumulate at tumor sites owing to the enhanced permeability and retention effect due to the presence of unorganized and fenestrated blood vessels and impaired 
lymphatic drainage. Hyperthermia can be achieved at the tumor with little to no adverse effects on surrounding healthy tissue. However, there are limitations to MNP hyperthermic therapies. These include a failure to achieve effective concentration of MNPs in the tumor due to clearance of MNPs by the RES [33]. Increasing MNP doses to promote therapeutic outcomes is limited by the maximum tolerated dose [34]. Increasing the magnetic field amplitude and/or frequency may lead to nonspecific eddy current heating of the surrounding tissue and promote toxicities [35]. Promotion of selective accumulation of MNPs at the tumor site can be facilitated by cancer-targeting ligands placed on the particle itself. For example, it has been shown that anti-HER2 immunoliposomes encapsulating MNPs permitted nanoparticle accumulation in breast cancer cells overexpressing HER2, followed by tumor-specific hyperthermia, raising the local temperature by $8{ }^{\circ} \mathrm{C}[36]$. Similarly, EGF receptor-targeted inhalable MNPs were shown to selectively accumulate in non-small-cell lung cancers. The potential of magnetic hyperthermia as an effective anticancer treatment can certainly be facilitated by such targeted MNPs [37].

In addition to inducing cancer cell apoptosis, magnetic hyperthermia stimulates innate immune responses. As tumor cell surveillance consists of natural killer cells and cytotoxic lymphocytes these are activated at $42{ }^{\circ} \mathrm{C}$ serving to eliminate the tumor [38]. Further more, local hyperthermia can result in homing of activated monocytes to the tumor through the release of pro-inflammatory factors that include che-mokines and promote influx of natural killer cells and cytotoxic T lymphocytes [39]. The mechanism for stimulation of the innate immune response involves the release of dead cell protein contents, most notably heat shock proteins, which activate monocytes from the tumor microenvironment. This is followed by induction of proinflammatory cytokines and further recruitment of antigen-presenting cells. Activation of the immune system in response to hyperthermia further diminishes invasion of new tumor cells [40]. Together, heat triggered apoptosis and the associated immune response can suppress both primary tumor mass and the metastatic lesions. Proof of concept for effectiveness of hyperthermia treatment using MNPs was demonstrated in clinical studies, where MNPs were used for thermotherapy of prostate tumors $[12,13]$ and recurrent glioblastoma multiforme [14]. The potential for thermotherapy was demonstrated in a European clinical study where MNPs were injected directly into pancreatic tumors; hyperthermic thermoablative temperatures were achieved in the prostate at low AMF strength [12,13]. In another clinical study, MNPs instilled intratumorally into patients with recurrent glioblastoma multiforme followed by heating using an AMF in conjunction with a reduced radiation dose [14] increased overall patient survival with only moderate side effects. These studies are promising, however, more work needs to be carried out to ensure that healthy surrounding tissues are not damaged by the hyperthermia and that heat distribution is evenly distributed throughout the tumor mass.

\section{Bioimaging}

Development of any effective treatment requires early and accurate noninvasive disease diagnosis. To this end, several different medical scanning modalities have been developed, such as PET, single-photon-emission computed tomography, optical fluorescence, ultrasound and MRI. MRI, in contrast to other imaging modalities, offers an ability to generate 3D images while providing superior spatial resolution and excellent signal-to-noise 
ratios without exposure to radiation. The underlying mechanism of MRI is alignment of water protons in a static magnetic field, excitation of protons by a radiofrequency current under an appropriate resonance frequency, followed by detection of proton relaxation signals and conversion of relaxation signals into an image $[6,41,42]$. There are two types of MRI contrast agents: contrast enhancement $\left(\mathrm{T}_{1}\right)$ and negative contrast $\left(\mathrm{T}_{2}\right)$. MNPs are negative contrast $\left(\mathrm{T}_{2}\right)$ agents. Upon exposure to an external magnetic field, the spin-spin relaxation time $\left(T_{2}\right)$ of water molecules surrounding MNPs is significantly reduced, resulting in darkening of the corresponding area in $\mathrm{T}_{2}$-weighted images. The extent to which $T_{2}$ is shortened is typically represented by spin-spin relaxivity $\left(R_{2}=1 / T_{2}\right)$, where a higher $R_{2}$ value implies enhanced contrast effects. The relaxivity coefficient $\left(r_{2}\right)$, determined as a gradient of plots of $\mathrm{R}_{2}$ against Fe concentration, can be used to standardize contrast enhancement. To date, a range of MNP formulations have been employed as MRI contrast agents. Most notable of these are Feridex IV ${ }^{\circledR}$, Endorem ${ }^{\circledR}$, Lumiren $^{\circledR}$, Combidex ${ }^{\circledR}$ (all from Advanced Magnetic Pharmaceuticals, MA, USA) and Resovist ${ }^{\circledR}$ (Bayer Schering Pharma AG, Leverkusen, Germany). Feridex was the first commercially available MNP formulation and is commonly used in imaging liver lesions. Endorem and Resovist have been used for the diagnosis of liver lesions and tumors, cardiac infarcts and brain lesions [11]. Lumiren has been employed for imaging of the bowel and Combidex for metastases of the lymph node [9]. However, two factors limit clinical application of MNP-based MRI contrast agents. The first is low $R_{2}$ values. There are several parameters, which correlate to $R_{2}$ values, specifically $R_{2}$ increases with saturation magnetization. In addition, MNPs can be further doped with paramagnetic atoms (e.g., manganese) to enhance their contrast abilities $[43,44]$. The second limiting factor is nonspecific uptake and clearance by the RES. MNPs, especially those of $>40 \mathrm{~nm}$ hydrodynamic radius, tend to accumulate in the liver and spleen, which can be utilized to detect tumors or lesions in these organs [41]. However, non-specific uptake of MNPs by the RES presents a major challenge to developing effective imaging modalities of other organs [43]. To overcome this limitation and to increase the contrast agent circulation time to desired tumor sites, strategies to prevent opsonization have been developed $[45,46]$. For example, coating MNPs with poly(ethylene glycol) (PEG) provides a steric barrier to RES clearance [47]. The improved circulation time allows utilizing the enhanced permeability and retention effect that accompanies many solid tumors, thus promoting accumulation of the contrast agent in tumors and allowing effective imaging of tumor sites.

Moreover, conjugation of tumor-targeting ligands to the MNP surface can improve their tumor-targeting capabilities [48]. Folic acid (FA)-targeted MNPs are produced for efficient MRI detection of tumors that overexpress the folate receptor. Significant accumulation of FA-targeted MNPs was reported in tumor xenografts [49]. Similarly, thermoresponsive MNPs tagged with prostate cancer-specific R11 peptides were prepared for selective accumulation of MNPs and imaging of prostate cancer [50]. Multimodality imaging probes have also been developed, wherein MNPs are combined with another imaging modality such as fluorescent dyes or radionuclides. Several systems were reported that incorporated the fluorescent dyes fluorescein isothiocyanate [51], Dil (a lipophilic cationic indocarbocyanine dye) [52] and indocyanine green [53] on the MNP surface to combine MRI with fluores-cent 
imaging. Additional multimodality imaging was achieved by combining tumor-targeting ligands, specifically oleanolic acid and ${ }^{68} \mathrm{Ga}$, for combined MRI and PET imaging [54].

More recently, MNPs were designed for image-guided drug delivery as novel theranostic platforms. In recent studies, $\mathrm{pH}$-sensitive MNPs conjugated with the antitumor drug doxorubicin demonstrated improved antitumor efficacy with application of a magnetic field [55]. In similar studies, doxorubicin-encapsulated MNPs were synthesized that allowed simultaneous tumor-targeted delivery and sensitive MRI detection [56]. Recently, hybrid polymersomes, constructed using micromixing, successfully incorporated the anticancer drug camptothecin and MNPs. These types of theranostic MNP nanoconstructs have also been engineered with the cancer-targeting peptide bombesin, as well as the fluorescent marker dye AlexaFluor ${ }^{\circledR} 647$ (Molecular Probes, Life Technologies, NY, USA) [57].

Theranostic uses for MNPs are being developed in our own laboratory [10]. SMART particles for the diagnosis and treatment of HIV infection were manufactured by encasing atazanavir and superparamagnetic iron oxide particles in a poly(lactic-co-glycolic) acid matrix and coating with 1,2-distearoyl-sn-glycero-3-phosphocholine, and 1,2-distearoyl-snglycero-3-phosphoethanolamine-mPEG. These particles are taken up by mononuclear phagocytes then stored and carried to sites of active viral replication. As a proof of concept, MRI and drug quantitation were used to determine biodistribution of the SMART particles following parenteral administration and demonstrated parallel distribution of magnetite and drug. Such particles could enable rapid assessment of drug biodistribution and allow screening of particles targeted to cells and tissues that harbor the virus (Figure 2).

\section{Drug delivery}

One of the limitations of most current therapeutics is their unfavorable pharmacokinetics and nonspecifc biodistribution profiles, which cause toxicities to healthy tissues. To overcome this limitation, nanoformulations are employed as a means to improve drug pharmacokinetics and pharmacodynamics. Targeting to specific disease sites can prolong circulation time and reduce drug dose and the occurrence of adverse effects, resulting in improved therapeutic efficacy and safety. These nanoconstructs can be engineered to undergo physical changes (e.g., degradation of shell) upon exposure to an external stimulus (e.g., temperature, light, $\mathrm{pH}$ and magnetic gradients) that lead to release of loaded drug at intended pathologic sites [58]. MNPs are also a promising approach to site-specific delivery of therapeutic payloads. These nanoparticles can be targeted to and retained at a desired site until the encapsulated drug is released by means of an applied external magnetic gradient; thereby reducing unwanted drug adverse effects by limiting nonspecific distribution [26,59].

The concept of targeted drug delivery by magnetic guidance (through an external or implanted magnetic gradient) was originally conceived in the early 1960s. The first preclinical experiments exploited magnetic guidance to hold magnetic microspheres (1-3 $\mu \mathrm{m}$ in size) within large arteries in dogs [60]. Subsequently, external magnetic fields were employed to accumulate magnetic albumin microspheres loaded with anticancer drug at a tumor site [61]. Since then, there have been a plethora of reports on the development of improved MNP-drug formulations for cancer therapy (e.g., doxorubicin, paclitaxel and 
methotrexate) [62-65]. In a Phase I clinical study, drug targeting employing MNPs is well tolerated in patients with advanced stage cancer and can deliver anticancer drug(s) to the tumor areas. Although the response to the treatment in most patients was low, such investigations provided proof of concept for the use of magnetic drug targeting [15].

For penetration into deeper tissues, implant magnets can be used. Implant-assisted magnetic drug targeting was evaluated in a pig model of thrombolytic therapy, with no short-term adverse effects [66]. Still, magnetically targeted MNPs have some limitations such as nonspecific uptake by the RES and difficulty in crossing the tissue and cellular barriers, which can be partially overcome with the use of MNPs with higher magnetic susceptibility and a stronger force field [28] or by combining additional targeting techniques. MNPs can be functionalized with cell-specific targeting molecules to accelerate intracellular accumulation. Several recent reports have demonstrated enhanced cancer cell targeting and drug delivery by drug-loaded MNPs that had been functionalized with FA in the presence of an applied magnetic field. Such carrier systems provided higher uptake in cancer cells than healthy cells and confined apoptosis to the cancer cells [62,67-68]. MNPs loaded with two drugs (i.e., the antitumor drug doxorubicin and the antiangiocardiopathy drug verapamil), followed by modification with the tumor targeting ligand cyclo(Arg-Gly-Asp-D-Phe-Lys) peptide demonstrated improved pharmacokinetics and pharmacody-namics. Rodent studies demonstrated biodistribution of the dual drug-loaded particles to the tumor site with reduction in tumor growth without untoward toxicity [69]. MNPs have also been developed to treat brain disorders by enhancing delivery of drugs across the blood-brain barrier (BBB) [70-73].

\section{Magnetofection}

Gene therapy, defined as expression of genetic material (DNA, siRNA and antisense oligodeoxynucleotides) in a patient's cells for therapeutic benefit, holds promise for treating genetically based diseases. However, instability of genetic material in physiological fluid and inadequate cellular diffusion impede therapeutic outcomes. To surmount these challenges, novel gene delivery methods have been employed for efficient gene transfection $[74,75]$. For instance, nanoparticle-based delivery systems have provided platforms for enabling gene therapy to reach its full potential by accelerating nucleic acid delivery to tissues and cells $[76,77]$.

To this end, magnetofection, defined as delivery of genetic material using cationic MNPs guided by magnetic forces, has been tested in proof-of-concept studies. Magnetofection was first described at the turn of the century [78,79]. Since its development, several research groups have optimized and implemented the concept of magnetic targeting and transfection of genetic materials. MNPs have been employed successfully for in vivo and in vitro transfection of plasmids, antisense oligodeoxynucleotides, siRNA and shRNA [48,80, 81].

For optimal transfection of genetic material, cell viability must be maintained. For this, the physicochemical properties of MNPs are crucial. Magnetic susceptibility of MNPs should be adequate enough to concentrate the vectors at the designated cells/tissues [82]. For efficient loading of nucleic acid, MNPs could be bridged to the nucleic acid with cationic polymers 
such as polyethyleneimine (PEI) and protamine sulfate [83,84]. PEI is the most frequently employed polymer for nucleic acid delivery because it facilitates lysosomal escape via the 'proton-sponge' mechanism [85]. The design can be improved further by grafting PEG to PEI, which subsequently reduces PEI-associated cytotoxicity [83]. Nucleic acids must be encapsulated inside the nanocarrier to maintain stability until they are released inside the cell [7].

Magnetofection can be an efficient and 'cell-friendly' approach for genetic manipulation of stem cells by introducing foreign DNA without adversely interfering with the cell cycle. Higher transfection efficacy of an enhanced green fluorescent protein reporter gene in murine embryonic stem cells with no adverse effects on cell differentiation/proliferation was observed using magnetofection compared with conventional transfection [86]. Similarly, magnetofection of primary human mesenchymal stem cells with green fluorescent protein plasmids resulted in higher transfection efficiency and improved cell viability [87].

Although, the underlying mechanism for enhanced transfection with MNPs is unclear, it is proposed that the static magnetic field assists transfection by accelerating particle interaction with cells, followed by uptake through endocytosis [88].

\section{Magnetic separation}

Magnetic separation is widely used for the separation and purification of cells [89], recombinant proteins [90], DNA [91] and monoclonal antibodies [92]. Separation of these biological constituents using MNPs involves attachment of biological constituents to surface-modified MNPs, followed by separation with the aid of an external magnetic force [93]. Cell separation using MNPs involves interaction of surface-modified particles with a cell, followed by internalization via receptor-mediated endocytosis or phagocytosis and subsequent separation using an applied magnetic field. The surface of the MNP is usually engineered with ligands that are efficiently internalized by the targeting cell, such as insulin, lactoferrin and FA, since these receptors are frequently expressed on the cell surface [11]. A novel column-free magnetic separation system using tetrameric antibody complexes with dual specificity for dextran-coated MNPs and the CD11b epitope of microglia was developed. This approach resulted in efficient and rapid separation of microglia with a recovery of $>97 \%$ purity [94]. In a similar study, magnetic cell separation technology was developed for the isolation of murine postnatal brain microglia, with high viability using CD11b-coated magnetic beads [95]. MNPs tagged with anti-CD4 antibody have also been used for the isolation of $\mathrm{CD} 4^{+} \mathrm{T}$ lymphocytes from whole human blood with a purity in excess of $95 \%$ [96].

Therapeutic proteins and monoclonal antibodies are fast growing markets with an estimated global value of US $\$ 107$ billion and US $\$ 86$ billion by 2015 , respectively. To meet the challenges of large-scale production, isolation and purification of these biopharmaceutics is of paramount importance. Magnetic separation is a well-established procedure for isolation and purification of recombinant protein and monoclonal bodies [93]. Immobilized MNPs modified with affinity tags, such as ion-exchange groups, can be used to separate tagged proteins with high efficiency and selectivity. Using this technique, negatively charged MNPs were shown to exhibit significant binding capacities for cytochrome C $(640 \mathrm{mg} / \mathrm{g})$ through 
cation exchange [97]. Surface functionalization of MNPs with metal ions such as $\mathrm{Ni}^{2+}$ and $\mathrm{Co}^{2+}$ has been used to selectively capture polyhistidine-tagged (His-tagged) proteins from cell extracts with subsequent separation using an appropriately applied magnetic field [98100]. In other studies, boronic acid-functionalized MNPs have been used extensively for one-step capture of human monoclonal antibodies with high yield and purity [101,102].

\section{Tissue engineering}

Tissue engineering offers new possibilities to surmount the organ transplantation crisis, especially due to shortage of donor organs. Tissue engineering involves isolation of cells from healthy tissue or stem cells (embryonic and pluripotent stem cells) and seeding cells onto a 3D scaffold. For this purpose, the scaffold is required to be biocompatible and nontoxic. Such scaffolds are frequently prepared from 'body-friendly' biocompatible and biodegradable polymers, sponges and agarose. The colonization of cells on these scaffolds can occur directly inside the body or can be initiated under ex vivo conditions followed by transplantation into the patient for regeneration of damaged tissue [7,103]. Alternatively, a bottom-up approach is practiced that comprises patterning cells onto a predefined structure, which directs further maturation of the tissue construct [104]. In both cases, growth factors are frequently added to accelerate proliferation and differentiation of the cells. In addition to growth factors, physical signaling such as mechanical stimulation and electrical signaling may be required for appropriate growth of artificial tissue. These signals attempt to mimic the biological signals inside the body required for cellular proliferation and differentiation [105].

It is difficult, however, to construct a functional organ that mimics the precision and complexity of the organ in vivo. The major challenge facing tissue engineering is an ineffective cell scaffold that impairs cell seeding and cell-cell interaction, especially between heterotypic cells and cell layers [7]. To overcome this difficulty, magnetic forcebased mechanical stimulation has been used. Cells labeled with MNPs and subjected to a magnetic force accumulate evenly over a scaffold and demonstrate homogenous growth in a manipulated direction. The shape of the artificial tissue is controlled by manipulating the magnetic force [106,107]. Magnetic cationic liposomes (MCLs) have been studied extensively for use in tissue engineering. MCLs employed for tissue engineering are usually made up of MNPs encapsulated into cationic liposomes composed of a lipid mixture consisting of $N$-(a-trimethylammonioacetyl)-didodecyl-D-glutamate chloride, dilauroyl phosphatidylcholine and dioleoylphosphati-dyl-ethanolamine in a 1:2:2 molar ratio $[108,109]$. MCLs were used to construct heterotypic layers of rat hepatocytes and human aortic endothelial cells (HAECs). The magnetically labeled HAECs preferentially migrated and adhered to the hepatocyte monolayers under the influence of an external magnetic force. By contrast, in the absence of a magnetic field, HAECs did not adhere to rat hepatocytes and did not construct a heterotypic co-culture layer, which was marked by less albumin secretion compared with the heterotypic layer [108]. MCLs may also be used for the successful regeneration of skeletal muscle tissue using 3D tissue-like constructs from MCL-labeled cells under an external magnetic force [109]. Although overall magnetic force-based processes in tissue engineering have been widely established, at a certain point of growth in a 3D cell cluster, the magnetic gradient reaches a value that is insufficient to concentrate 
cells. To address this issue, a novel magnetic pin system was designed to generate uniform 3D cell clusters. Combining an iron pin and magnet provided a concentrated and strong magnetic field at a specific point and reinforced efficient cell-cell interactions to construct uniform 3D cell clusters with enhanced cell functions [110].

\section{Nanoneuromedicine}

The CNS, and the brain in particular, is protected by the BBB, which protects against infiltration by bacteria, viruses and other foreign materials [111]. Approximately $98 \%$ of potentially active drugs for brain-related disorders are unable to reach therapeutically relevant concentrations in the brain, primarily because of the BBB [59]. It follows that the efficacies of CNS-active agents could be predicted by their ability to cross the BBB. Only small lipid-soluble molecules with a molecular mass $<400$ Da can cross the BBB via passive diffusion and reach the brain at therapeutic concentrations. Unfortunately, most CNS drugs either have a molecular mass greater than the desired window or are too hydrophilic to enter into the brain by passive diffusion [111]. Many drugs are administered at high doses in order to achieve therapeutic levels in the brain; this results in peripheral side effects [112]. Most pharmaceutical agents in the absence of drug delivery technology get into the brain via traditional, yet ineffective brain delivery systems, such as BBB disruption [113] and transcranial delivery [114]. Opening of the BBB, such as osmotic opening of tight junctions, even for transient periods is associated with neuropathological changes, which lead to chronic toxicity and jeopardized clinical outcomes [115]. Transcranial delivery is limited to delivery of drugs around the injection site and is ineffective for uniform distribution of drug to the entire brain [114]. In order to deliver drugs to the brain, there is a need to develop safe and efficacious brain drug delivery technologies. To date, various brain-targeting strategies and delivery systems have been developed to cope with this problem. Some of those used prominently include: chemical drug delivery systems, such as lipid-mediated delivery [116], prodrug approaches [117] and lock-in delivery [118]; specific re-engineering of pharmaceutical agents to be substrates for endogenous transporters found on brain endothelial capillaries [119]; molecular Trojan horses [120]; and the use of carrier systems such as liposomes [121], dendrimers [122] and polymeric nanoparticles [123]. MNPs of hydrodynamic radius $<100 \mathrm{~nm}$ are not immediately recognized by mononuclear phagocytes [17] and have a longer blood half-life and a potential for CNS imaging and drug delivery because of their ability to be attracted to the CNS with the application of an external magnetic field. MNP-based nanoconstructs have demonstrated their utility for cellular labeling/cell-separation [96], targeted delivery [61] and hyperthermia, but have only recently been investigated for brain targeting [124]. However, recent studies have indicated that MNP-based biofunctional nanoconstructs, under the infuence of an external magnetic force, can indeed be a promising platform to circumvent the BBB and deliver therapeutic cargo to the CNS (Figure 3) [26,59].

In general, two kinds of brain-targeting strategies were employed using MNPs. In the first strategy, an external magnetic field is applied to direct the movement of MNP-encapsulated therapeutic cargo to the brain. Magnetic therapy using MNPs prolonged the survival of glioma-bearing rats by enhancing the brain concentration of paclitaxel [125]. In a similar report, in a rat model, magnetic targeting prolonged the retention of MNPs within gliomas, 
resulting in a fivefold increase in nanoparticle accumulation within targeted tumors compared with nontargeted tumors [4]. In a second rodent study, intracarotid administration of PEI-modified MNPs in conjunction with magnetic targeting resulted in increased accumulation at brain tumor sites [126,127]. In addition, delivery of imaging agents was improved significantly using MNPs with an applied magnetic field [59].

In the second strategy, MNPs are modified with various functional ligands including antibodies, peptides and proteins, which target specific receptors on brain cells most notably on the endothelial cells of the BBB [26,71]. As one example, penetration of MNPs modified with a transferrin receptor antibody into the brain is increased through interaction with the transferrin receptor on brain endothelial cells [128]. There are many other bioactive moieties that can be used to modify MNPs to enhance their transport through the BBB via receptormediated endocytosis. Qiao et al. demonstrated that modification of PEG-coated MNPs with lactoferrin-enhanced the permeability of the nanoparticles across the BBB by receptormediated endocytosis via interaction with the lactoferrin receptor on brain endothelial cells [129]. MNPs can also be modified with other functional groups that aid penetration across the BBB through interaction with key BBB proteins. For example, the HIV-1 TAT protein interacts with tight junction proteins and adhesion molecules to enhance BBB permeability [130]. When TAT was used to functionalize magnetic polymeric liposomes, permeability across the BBB was enhanced compared with nonfunctionalized MNPs when a magnetic field was applied, and significant accumulation of particles at a site of spinal cord injury was observed [131].

\section{Challenges}

MNPs have been developed for numerous biomedical applications, especially in the area of drug delivery and targeting. However, to translate these studies to clinical application many issues still must be resolved. In this section, we will briefly discuss some of the notable challenges facing the development of MNPs for in vivo applications. First, given the vast scope of MNP formulations for numerous biomedical applications, the studies evaluating potential toxic effects of MNPs are very limited in number. In spite of hopeful in vivo data that support MNP safety in preclinical and clinical studies [132-134], discrepancies exist in the literature concerning the safety of MNPs for human use. Several groups have reported that excessive release of free iron from MNPs facilitates the generation of free radicals, which can lead to oxidative stress and disruption in liver metabolism [135,136]. Pulmonary toxicity of MNPs was observed in adult male Wistar rats at a dose of $5 \mathrm{mg} / \mathrm{kg}$ iron [137]. In a recent study, polyacrylic acid-coated MNPs at a concentration of $10 \mathrm{mg} / \mathrm{kg}$ in mice did not impair kidney function, but temporarily reduced blood pressure by decreasing arterial contractility [138]. Furthermore, excess accumulation of MNPs in the brain has been reported to lead to oxidative stress through abnormal interaction of iron with brain proteins (amyloid- $\beta$ peptide or neuromelanin), which have been associated with the development of neurodegenerative disorders, such as Parkinson's disease, Alzheimer's disease and multiple sclerosis $[139,140]$. Thus, it is critical to identify the toxicities of MNP formulations prior to clinical use. It has been well accepted that physiochemical properties (e.g., shape, size, surface charge and surface coating) of MNPs are critical in determining the toxic potential 
of MNPs [141]. However, more experimental evidence is required to identify a safe dose and formulation of MNPs with optimal clinical benefits and reduced risks.

Another challenge in the development of MNPs for appropriate biomedical applications is limiting the clearance of MNPs by the liver and spleen. In this regard, the size and surface coating of MNPs are critical to avoiding scavenging by the RES and reducing aggregation [142]. Moreover, with appropriate surface coating and conjugation of specific targeting ligands, along with magnetic targeting, it is possible to enhance the accumulation of drugloaded MNPs at the target tissue [26,143]. Furthermore, improved magnetic properties of MNPs can optimize MNPs for drug delivery, MRI and hyperthermia. Use of ferrites (e.g., $\mathrm{CoFe}_{2} \mathrm{O}_{4}$ and $\mathrm{MnFe}_{2} \mathrm{O}_{4}$ ) and fabrication of core-shell nanoconstruct systems have provided improvements in hyperthermia applications [144]. Another pitfall for using MNPs as drug delivery vehicles is the lack of an effective magnetic field gradient for deep organs and blood vessels. To overcome this obstacle, the use of superconducting magnets such as $\mathrm{SmBaCuO}$ and $\mathrm{YBaCuO}$, which can exert strong magnetic gradients to penetrate the skin surface to a depth of $20 \mathrm{~mm}$ has been proposed [145]. Much effort will be required to translate MNP technology to clinical applications. Despite the pros and cons of using MNPbased nanoconstructs for in vivo applications, superparamagnetic iron oxide nanoparticles are one of the nanomedicines that have been approved for clinical use to date.

\section{Conclusion}

The developing interest in the biomedical application of nanotechnology has led to the development of nanomedicines. In recent years, extensive research has shown that MNPs can be a promising tool for translational biomedical applications. In the last decade, MNPbased therapeutics have led to new opportunities for diverse medical therapeutic disciplines such as hyperthermia, tissue implant engineering, gene delivery, drug delivery and magnetic-based protein purifcations. MNP synthesis and development take advantage of integration strategies in physics, chemistry, biology and engineering. To date, various MNP formulations have been developed for MRI contrast agents, magnetic hyperthermia and image-guided drug delivery. The last decade has witnessed an expansion of MNP research activities to realize the potential of therapeutic drug delivery exceeding those seen with conventional systems. While MNP-based technologies appear to hold a significant potential for a myriad of biomedical applications, the toxic potential of MNPs cannot be overlooked. Further studies are required to identify a safe dose and formulation of MNPs with optimal clinical benefits and reduced risks. Moreover, advancements in nanotechnology are needed such as development of particles with enhanced magnetic properties, polymeric coating and the integration of multifunctional biological moieties. Understanding the relationship between the physicochemical properties of MNP constructs and their behavior will yield full translational potential of these nanoparticles.

\section{Future perspective}

MNP-based nanoparticulate systems with functional properties that allow distinct compositions of magnetic gradients have the potential for a range of novel clinical interventions. The ability to manipulate and remotely control certain cell-drug interactions 
would endow clinicians and scientists with powerful tools to investigate cellular function and signaling to ameliorate disease. Potential uses of MNPs include tissue implants, organ regeneration, drug delivery and improved diagnostics. Examples include magnetic ferrofluid utilized in eye surgery, magnetic targeting of cancers and tumor imaging [15,146,147]. Interdisciplinary research bringing together the fields of biology, chemistry, physics and engineering can yield new MNP-based technologies for improving global health.

\section{Acknowledgments}

This work was supported by US NIH grants 1P01DA028555, 2R01NS034239, 2R01NS36126, P01NS43985, P30RR031151 and P01MH64570. The authors thank Tatiana Bronich for critical reading of the manuscript, sharing of noteworthy ideas and lively and continuous discussions.

\section{References}

Papers of special note have been highlighted as:

- of interest

1. Kumari A, Yadav SK, Yadav SC. Biodegradable polymeric nanoparticles based drug delivery systems. Colloid. Surf. B. Biointerface. 2010; 75(1):1-18.

2. Kim BY, Rutka JT, Chan WC. Nanomedicine. N. Engl. J. Med. 2010; 363(25):2434-2443. [PubMed: 21158659]

3. Veiseh O, Gunn JW, Zhang M. Design and fabrication of magnetic nanoparticles for targeted drug delivery and imaging. Adv. Drug Deliv. Rev. 2010; 62(3):284-304. [PubMed: 19909778] • Considers current status and promising future use of magnetic nanoparticles (MNPs) in nanomedicine.

4. Chertok B, Moffat BA, David AE, et al. Iron oxide nanoparticles as a drug delivery vehicle for MRI monitored magnetic targeting of brain tumors. Biomaterials. 2008; 29(4):487-496. [PubMed: 17964647]

5. Mahajan SD, Aalinkeel R, Law WC, et al. Anti-HIV-1 nanotherapeutics: promises and challenges for the future. Int. J. Nanomed. 2012; 7:5301-5314.

6. Colombo M, Carregal-Romero S, Casula MF, et al. Biological applications of magnetic nanoparticles. Chem. Soc. Rev. 2012; 41(11):4306-4334. [PubMed: 22481569] • Presents an extensive overview of fundamental aspects of MNPs with an eye to optimum biomedical applications.

7. Reddy LH, Arias JL, Nicolas J, Couvreur P. Magnetic nanoparticles: design and characterization, toxicity and biocompatibility, pharmaceutical and biomedical applications. Chem. Rev. 2012; 112(11):5818-5878. [PubMed: 23043508]

8. Krishnan KM. Biomedical nanomagnetics: a spin through possibilities in imaging, diagnostics, and therapy. IEEE Transact. Magn. 2010; 46(7):2523-2558.

9. Wang YX, Hussain SM, Krestin GP. Superparamagnetic iron oxide contrast agents: physicochemical characteristics and applications in MR imaging. Eur. Radiol. 2001; 11(11):23192331. [PubMed: 11702180]

10. Guo D, Li T, McMillan J, et al. Small magnetite antiretroviral therapeutic nanoparticle probes for MRI of drug biodistribution. Nanomedicine (Lond.). 2013 (Epub ahead of print). Describes development and use of small magnetite antiretroviral therapeutic particles for assessing drug pharmacokinetics and biodistribution by MRI.

11. Banerjee R, Katsenovich Y, Lagos L, Mclintosh M, Zhang X, Li CZ. Nanomedicine: magnetic nanoparticles and their biomedical applications. Curr. Med. Chem. 2010; 17(27):3120-3141. [PubMed: 20629620]

12. Johannsen M, Gneveckow U, Eckelt L, et al. Clinical hyperthermia of prostate cancer using magnetic nanoparticles: presentation of a new interstitial technique. Int. J. Hypertherm. 2005; 21(7):637-647. 
13. Johannsen M, Thiesen B, Wust P, Jordan A. Magnetic nanoparticle hyperthermia for prostate cancer. Int. J. Hypertherm. 2010; 26(8):790-795.

14. Maier-Hauff K, Ulrich F, Nestler D, et al. Efficacy and safety of intratumoral thermotherapy using magnetic iron-oxide nanoparticles combined with external beam radiotherapy on patients with recurrent glioblastoma multiforme. J. Neurooncol. 2011; 103(2):317-324. [PubMed: 20845061]

15. Lubbe AS, Bergemann C, Riess H, et al. Clinical experiences with magnetic drug targeting: a phase I study with 4'-epidoxorubicin in 14 patients with advanced solid tumors. Cancer Res. 1996; 56(20):4686-4693. [PubMed: 8840985]

16. Choi HS, Liu W, Misra P, et al. Renal clearance of quantum dots. Nat. Biotechnol. 2007; 25(10): 1165-1170. [PubMed: 17891134] • Presents a detailed study on the clearance mechanisms for nanoparticulate systems.

17. Shubayev VI, Pisanic TR 2nd, Jin S. Magnetic nanoparticles for theragnostics. Adv. Drug Deliv. Rev. 2009; 61(6):467-477. [PubMed: 19389434]

18. Gratton SE, Ropp PA, Pohlhaus PD, et al. The effect of particle design on cellular internalization pathways. Natl Acad. Sci. USA. 2008; 105(33):11613-11618.

19. Chithrani BD, Ghazani AA, Chan WC. Determining the size and shape dependence of gold nanoparticle uptake into mammalian cells. Nano Lett. 2006; 6(4):662-668. [PubMed: 16608261]

20. Chithrani BD, Chan WC. Elucidating the mechanism of cellular uptake and removal of proteincoated gold nanoparticles of different sizes and shapes. Nano Lett. 2007; 7(6):1542-1550. [PubMed: 17465586]

21. Huang X, Li L, Liu T, et al. The shape effect of mesoporous silica nanoparticles on biodistribution, clearance, and biocompatibility in vivo . ACS Nano. 2011; 5(7):5390-5399. [PubMed: 21634407]

22. Albanese A, Tang PS, Chan WC. The effect of nanoparticle size, shape, and surface chemistry on biological systems. Ann. Rev. Biomed. Eng. 2012; 14:1-16. [PubMed: 22524388]

23. Alexis F, Pridgen E, Molnar LK, Farokhzad OC. Factors affecting the clearance and biodistribution of polymeric nanoparticles. Mol. Pharmaceut. 2008; 5(4):505-515. • Focuses on the physicochemical and biological aspects of nanop articulate systems that influence their clearance and biodistribution by avoiding the reticuloendothelial system.

24. Lu AH, Salabas EL, Schuth F. Magnetic nanoparticles: synthesis, protection, functionalization, and application. Angew. Chem. Int. Ed. Engl. 2007; 46(8):1222-1244. [PubMed: 17278160]• Presents a detaliled overeview of the synthesis procedures for MNPs.

25. Gupta AK, Naregalkar RR, Vaidya VD, Gupta M. Recent advances on surface engineering of magnetic iron oxide nanoparticles and their biomedical applications. Nanomedicine (Lond.). 2007; 2(1):23-39. [PubMed: 17716188]

26. Cui Y, Xu Q, Chow PK, Wang D, Wang CH. Transferrin-conjugated magnetic silica PLGA nanoparticles loaded with doxorubicin and paclitaxel for brain glioma treatment. Biomaterials. 2013; 34(33):8511-8520. [PubMed: 23932498]

27. Gordon RT, Hines JR, Gordon D. Intracellular hyperthermia. A biophysical approach to cancer treatment via intracellular temperature and biophysical alterations. Med. Hypoth. 1979; 5(1):83102.

28. Wust P, Hildebrandt B, Sreenivasa G, et al. Hyperthermia in combined treatment of cancer. Lancet Oncol. 2002; 3(8):487-497. [PubMed: 12147435]

29. Xu Y, Karmakar A, Heberlein WE, Mustafa T, Biris AR, Biris AS. Multifunctional magnetic nanoparticles for synergistic enhancement of cancer treatment by combinatorial radio frequency thermolysis and drug delivery. Adv. Healthcare Mat. 2012; 1(4):493-501.

30. Owen J, Pankhurst Q, Stride E. Magnetic targeting and ultrasound mediated drug delivery: benefits, limitations and combination. Int. J. Hypertherm. 2012; 28(4):362-373. • Reviews the use of magnetism and ultrasound for therapeutic delivery with particular emphasis on the technique of magnetic microbubbles.

31. Gonzales-Weimuller M, Zeisberger M, Krishnan KM. Size-dependant heating rates of iron oxide nanoparticles for magnetic fluid hyperthermia. J. Magn. Magn. Mater. 2009; 321(13):1947-1950.

32. Purushotham S, Ramanujan RV. Thermoresponsive magnetic composite nanomaterials for multimodal cancer therapy. Acta Biomat. 2010; 6(2):502-510. 
33. Shokrollahi H. Structure, synthetic methods, magnetic properties and biomedical applications of ferrofluids. Mat. Sci. Eng. C Mater. Biol. Appl. 2013; 33(5):2476-2487.

34. Khandhar AP, Ferguson RM, Simon JA, Krishnan KM. Tailored magnetic nanoparticles for optimizing magnetic fluid hyperthermia. J. Biomed. Mater. Res. A. 2012; 100(3):728-737. [PubMed: 22213652]

35. Ivkov R, DeNardo SJ, Daum W, et al. Application of high amplitude alternating magnetic fields for heat induction of nanoparticles localized in cancer. Clin. Cancer. Res. 2005; 11(19 Pt 2): 7093s-7103s. [PubMed: 16203808]

36. Kikumori T, Kobayashi T, Sawaki M, Imai T. Anti-cancer effect of hyperthermia on breast cancer by magnetite nanoparticle-loaded anti-HER2 immunoliposomes. Br. Cancer Res. Treat. 2009; 113(3):435-441. - Describes the use of anti-HER2 immunoliposomes containing magnetite particles for hyperthermia treatment of BT474 tumors in nude mice.

37. Sadhukha T, Wiedmann TS, Panyam J. Inhalable magnetic nanoparticles for targeted hyperthermia in lung cancer therapy. Biomaterials. 2013; 34(21):5163-5171. [PubMed: 23591395]

38. Kawai N, Ito A, Nakahara Y, et al. Anticancer effect of hyperthermia on prostate cancer mediated by magnetite cationic liposomes and immune-response induction in transplanted syngeneic rats. Prostate. 2005; 64(4):373-381. [PubMed: 15754344]

39. Kubes J, Svoboda J, Rosina J, Starec M, Fiserova A. Immunological response in the mouse melanoma model after local hyperthermia. Physiol. Res. 2008; 57(3):459-465. [PubMed: 17552874]

40. Multhoff G. Hyperthermia classic commentary: activation of natural killer (NK) cells by heat shock protein 70, Gabriele Multhoff, International Journal of Hyperthermia, 18, 576-585. Int. J. Hypertherm. 2009; 25(3):176-179. (2002).

41. Qiao R, Yang C, Gao M. Superparamagnetic iron oxide nanoparticles: from preparations to in vivo MRI applications. J. Mater. Chem. 2009; 19(35):6274-6293.

42. Hao R, Xing R, Xu Z, Hou Y, Gao S, Sun S. Synthesis, functionalization, and biomedical applications of multifunctional magnetic nanoparticles. Adv. Mater. 2010; 22(25):2729-2742. [PubMed: 20473985]

43. Singamaneni S, Bliznyuk VN, Binek C, Tsymbal EY. Magnetic nanoparticles: recent advances in synthesis, self-assembly and applications. J. Mater. Chem. 2011; 21(42):16819-16845.

44. Yoo D, Lee JH, Shin TH, Cheon J. Theranostic magnetic nanoparticles. Acc. Chem. Res. 2011; 44(10):863-874. [PubMed: 21823593]

45. Ruoslahti E, Bhatia SN, Sailor MJ. Targeting of drugs and nanoparticles to tumors. J. Cell Biol. 2010; 188(6):759-768. [PubMed: 20231381]

46. Moghimi SM, Hunter AC, Murray JC. Long-circulating and target-specific nanoparticles: theory to practice. Pharmacol. Rev. 2001; 53(2):283-318. [PubMed: 11356986]

47. Harris JM, Chess RB. Effect of pegylation on pharmaceuticals. Nat. Rev. Drug Discov. 2003; 2(3): 214-221. [PubMed: 12612647] • Describes the fundamentals of nanoparticle PEGylation to bypass the reticuloendothelial system.

48. Wang C, Ding C, Kong M, et al. Tumor-targeting magnetic lipoplex delivery of short hairpin RNA suppresses IGF-1R overexpression of lung adenocarcinoma A549 cells in vitro and in vivo. Biochem. Biophy. Res. Comm. 2011; 410(3):537-542.

49. Li J, Zheng L, Cai H, et al. Polyethyleneimine-mediated synthesis of folic acid-targeted iron oxide nanoparticles for in vivo tumor MR imaging. Biomaterials. 2013; 34(33):8382-8392. [PubMed: 23932250]

50. Wadajkar AS, Menon JU, Tsai YS, et al. Prostate cancer-specific thermo-responsive polymercoated iron oxide nanoparticles. Biomaterials. 2013; 34(14):3618-3625. [PubMed: 23419645]

51. Wang L, Neoh KG, Kang ET, Shuter B, Wang SC. Biodegradable magnetic-fluorescent magnetite/ poly(dl-lactic acid-co-alpha,beta-malic acid) composite nanoparticles for stem cell labeling. Biomaterials. 2010; 31(13):3502-3511. [PubMed: 20144844]

52. Odintsov B, Chun JL, Berry SE. Whole body MRI and fluorescent microscopy for detection of stem cells labeled with superparamagnetic iron oxide (SPIO) nanoparticles and DiI following intramuscular and systemic delivery. Methods Mol. Biol. 2013; 1052:1-17. [PubMed: 23640252] 
53. Ma Y, Tong S, Bao G, Gao C, Dai Z. Indocyanine green loaded SPIO nanoparticles with phospholipid-PEG coating for dual-modal imaging and photothermal therapy. Biomaterials. 2013; 34(31):7706-7714. [PubMed: 23871538]

54. Kim SM, Chae MK, Yim MS, et al. Hybrid PET/MR imaging of tumors using an oleanolic acidconjugated nanoparticle. Biomaterials. 2013; 34(33):8114-8121. [PubMed: 23932293]

55. Zhu L, Wang D, Wei X, et al. Multifunctional pH-sensitive superparamagnetic iron-oxide nanocomposites for targeted drug delivery and MR imaging. J. Control. Release. 2013; 169(3): 228-238. [PubMed: 23485450]

56. Yang X, Grailer JJ, Rowland IJ, et al. Multifunctional stable and $\mathrm{pH}$-responsive polymer vesicles formed by heterofunctional triblock copolymer for targeted anticancer drug delivery and ultrasensitive MR imaging. ACS Nano. 2010; 4(11):6805-6817. [PubMed: 20958084]

57. Bleul R, Thiermann R, Marten GU, et al. Continuously manufactured magnetic polymersomes - a versatile tool (not only) for targeted cancer therapy. Nanoscale. 2013; 5(23):11385-11393. [PubMed: 23820598] • Describes the production of polymeric vesicles containing drug and magnetite using micromixing technology.

58. Colson YL. Grinstaff MW Biologically responsive polymeric nanoparticles for drug delivery. Adv. Mater. 2012; 24(28):3878-3886. [PubMed: 22988558] • Review of responsive nanoparticles that release their drug cargo in response to $\mathrm{pH}$ or oxidative stress for functionally targeted drug delivery.

59. Kirthivasan B, Singh D, Bommana MM, Raut SL, Squillante E, Sadoqi M. Active brain targeting of a fluorescent P-gp substrate using polymeric magnetic nanocarrier system. Nanotechnology. 2012; 23(25):255102. [PubMed: 22652439]

60. Meyers PH, Cronic F, Nice CM Jr. Experimental approach in the use and magnetic control of metallic iron particles in the lymphatic and vascular system of dogs as a contrast and isotopic agent. Am. J. Roentgenol. Radium Ther. Nucl. Med. 1963; 90:1068-1077.

61. Widder KJ, Senyei AE, Ranney DF. Magnetically responsive microspheres and other carriers for the biophysical targeting of antitumor agents. Adv. Pharmacol. Chemother. 1979; 16:213-271. [PubMed: 382799]

62. Li D, Zhang YT, Yu M, Guo J, Chaudhary D, Wang CC. Cancer therapy and fluorescence imaging using the active release of doxorubicin from MSPs/Ni-LDH folate targeting nanoparticles. Biomaterials. 2013; 34(32):7913-7922. [PubMed: 23886730]

63. Rudzka K, Viota JL, Munoz-Gamez JA, Carazo A, Ruiz-Extremera A, Delgado AV. Nanoengineering of doxorubicin delivery systems with functionalized maghemite nanoparticles. Colloid. Surf. B. Biointerface. 2013; 111C:88-96.

64. Jain TK, Richey J, Strand M, Leslie-Pelecky DL, Flask CA, Labhasetwar V. Magnetic nanoparticles with dual functional properties: drug delivery and magnetic resonance imaging. Biomaterials. 2008; 29(29):4012-4021. [PubMed: 18649936]

65. Corem-Salkmon E, Ram Z, Daniels D, et al. Convection-enhanced delivery of methotrexate-loaded maghemite nanoparticles. Int. J. Nanomed. 2011; 6:1595-1602.

66. Kempe H, Kempe M. The use of magnetite nanoparticles for implant-assisted magnetic drug targeting in thrombolytic therapy. Biomaterials. 2010; 31(36):9499-9510. [PubMed: 20732712]

67. Licciardi M, Scialabba C, Cavallaro G, Sangregorio C, Fantechi E, Giammona G. Cell uptake enhancement of folate targeted polymer coated magnetic nanoparticles. J. Biomed. Nanotechnol. 2013; 9(6):949-964. [PubMed: 23858959]

68. Sahoo B, Devi KS, Banerjee R, Maiti TK, Pramanik P, Dhara D. Thermal and pH responsive polymer-tethered multifunctional magnetic nanoparticles for targeted delivery of anticancer drug. ACS Appl. Mater. Interface. 2013; 5(9):3884-3893.

69. Shen JM, Gao FY, Yin T, et al. cRGD-functionalized polymeric magnetic nanoparticles as a dualdrug delivery system for safe targeted cancer therapy. Pharmacol. Res. 2013; 70(1):102-115. [PubMed: 23376353]

70. Thomsen LB, Linemann T, Pondman KM, et al. Uptake and transport of superparamagnetic iron oxide nanoparticles through human brain capillary endothelial cells. ACS Chem. Neurosci. 2013; 4(10):1352-1360. [PubMed: 23919894] 
71. Yan F, Wang Y, He S, Ku S, Gu W, Ye L. Transferrin-conjugated, fluorescein-loaded magnetic nanoparticles for targeted delivery across the blood-brain barrier. J. Mater. Sci. Mater. Med. 2013; 24(10):2371-2379. [PubMed: 23793566]

72. Fan CH, Ting CY, Lin HJ, et al. SPIO-conjugated, doxorubicin-loaded microbubbles for concurrent MRI and focused-ultrasound enhanced brain-tumor drug delivery. Biomaterials. 2013; 34(14):3706-3715. [PubMed: 23433776]

73. Nair M, Guduru R, Liang P, Hong J, Sagar V, Khizroev S. Externally controlled on-demand release of anti-HIV drug using magneto-electric nanoparticles as carriers. Nat. Commun. 2013; 4:1707. [PubMed: 23591874]

74. Davis ME. Non-viral gene delivery systems. Curr. Opin. Biotechnol. 2002; 13(2):128-131. [PubMed: 11950563]

75. Guo X, Huang L. Recent advances in nonviral vectors for gene delivery. Acc. Chem. Res. 2012; 45(7):971-979. [PubMed: 21870813]

76. Miele E, Spinelli GP, Miele E, et al. Nanoparticle-based delivery of small interfering RNA: challenges for cancer therapy. Int. J. Nanomed. 2012; 7:3637-3657.

77. Yang J, Hendricks W, Liu G, et al. A nanoparticle formulation that selectively transfects metastatic tumors in mice. Proc. Natl Acad. Sci. 2013; 110(36):14717-14722. [PubMed: 23959886]

78. Plank C, Zelphati O, Mykhaylyk O. Magnetically enhanced nucleic acid delivery. Ten years of magnetofection-progress and prospects. Adv. Drug Deliv. Rev. 2011; 63:14-15. 1300-1331.

79. Schwerdt JI, Goya GF, Calatayud MP, Herenu CB, Reggiani PC, Goya RG. Magnetic fieldassisted gene delivery: achievements and therapeutic potential. Curr. Gene Ther. 2012; 12(2):116126. [PubMed: 22348552]

80. Jiang S, Eltoukhy AA, Love KT, Langer R, Anderson DG. Lipidoid-coated iron oxide nanoparticles for efficient DNA and siRNA delivery. Nano Lett. 2013; 13(3):1059-1064. [PubMed: 23394319]

81. Wen M, Li B, Ouyang Y, Luo Y, Li S. Preparation and quality test of superparamagnetic iron oxide labeled antisense oligodeoxynucleotide probe: a preliminary study. Ann. Biomed. Eng. 2009; 37(6):1240-1250. [PubMed: 19337837]

82. Prosen L, Prijic S, Music B, Lavrencak J, Cemazar M, Sersa G. Magnetofection: a reproducible method for gene delivery to melanoma cells. BioMed. Res. Int. 2013; 2013:209452. [PubMed: 23862136]

83. Kievit FM, Veiseh O, Bhattarai N, et al. PEI-PEG-chitosan copolymer coated iron oxide nanoparticles for safe gene delivery: synthesis, complexation, and transfection. Adv. Funct. Mater. 2009; 19(14):2244-2251. [PubMed: 20160995]

84. Morishita N, Nakagami H, Morishita R, et al. Magnetic nanoparticles with surface modification enhanced gene delivery of HVJ-E vector. Biochem. Biophy. Res. Comm. 2005; 334(4):11211126.

85. Patnaik S, Gupta KC. Novel polyethylenimine-derived nanoparticles for in vivo gene delivery. Expert Opin. Drug Deliv. 2013; 10(2):215-228. [PubMed: 23252504]

86. Lee CH, Kim EY, Jeon K, et al. Simple, efficient, and reproducible gene transfection of mouse embryonic stem cells by magnetofection. Stem Cell. Develop. 2008; 17(1):133-141.

87. Fouriki A, Dobson J. Oscillating magnet array-based nanomagnetic gene transfection of human mesenchymal stem cells. Nanomedicine (Lond.). 2013 Epub ahead of print.

88. Adams CF, Pickard MR, Chari DM. Magnetic nanoparticle mediated transfection of neural stem cell suspension cultures is enhanced by applied oscillating magnetic fields. Nanomed. Nanotechnol. Biol. Med. 2013; 9(6):737-741.

89. Earhart CM, Hughes CE, Gaster RS, et al. Isolation and mutational analysis of circulating tumor cells from lung cancer patients with magnetic sifters and biochips. Lab Chip. 2014; 14(1):78-88. [PubMed: 23969419]

90. Zhang L, Zhu X, Jiao D, Sun Y, Sun H. Efficient purification of His-tagged protein by superparamagnetic $\mathrm{Fe}_{3} \mathrm{O}_{4} / \mathrm{Au}-\mathrm{ANTA}-\mathrm{Co}^{2+}$ nanoparticles. Mat. Sci. Eng. C Mater. Biol. Appl. 2013; 33(4):1989-1992. 
91. Intorasoot S, Srirung R, Intorasoot A. Ngamratanapaiboon S. Application of gelatin-coated magnetic particles for isolation of genomic DNA from bacterial cells. Analyt. Biochem. 2009; 386(2):291-292. [PubMed: 19167338]

92. Borlido L, Moura L, Azevedo AM, Roque AC, Aires-Barros MR, Farinha JP. Stimuli-responsive magnetic nanoparticles for monoclonal antibody purification. Biotechnol. J. 2013; 8(6):709-717. [PubMed: 23420794] - Describes the use of stimuli-responsive magnetic particles with a polymer core and cross-linked polymer shell for purification of monoclonal antibodies from Chinese hamster ovary cell supernatant.

93. Whitesides GM, Kazlauskas RJ, Josephson L. Magnetic separations in biotechnology. Trends Biotechnol. 1983; 1(5):144-148.

94. Gordon R, Hogan CE, Neal ML, Anantharam V, Kanthasamy AG, Kanthasamy A. A simple magnetic separation method for high-yield isolation of pure primary microglia. J. Neurosci. Method. 2011; 194(2):287-296.

95. Harms AS, Tansey MG. Isolation of murine postnatal brain microglia for phenotypic characterization using magnetic cell separation technology. Methods Mol. Biol. 2013; 1041:33-39. [PubMed: 23813367]

96. Pimpha N, Chaleawlertumpon S, Chruewkamlow N, Kasinrerk W. Preparation of anti-CD4 monoclonal antibody-conjugated magnetic poly(glycidyl methacrylate) particles and their application on $\mathrm{CD}^{+}{ }^{+}$lymphocyte separation. Talanta. 2011; 84(1):89-97. [PubMed: 21315903]

97. Ditsch A, Yin J, Laibinis PE, Wang DIC, Hatton TA. Ion-exchange purification of proteins using magnetic nanoclusters. Biotechnol. Prog. 2006; 22(4):1153-1162. [PubMed: 16889393]

98. Lee KS, Lee IS. Decoration of superparamagnetic iron oxide nanoparticles with $\mathrm{Ni}^{2+}$ : agent to bind and separate histidine-tagged proteins. Chem. Commun. (Camb.). 2008; 6:709-711. [PubMed: 18478698]

99. Liu Z, Li M, Yang X, Yin M, Ren J, Qu X. The use of multifunctional magnetic mesoporous core/ shell heteronanostructures in a biomolecule separation system. Biomaterials. 2011; 32(21):46834690. [PubMed: 21481453]

100. Benelmekki M, Xuriguera E, Caparros C, et al. Design and characterization of $\mathrm{Ni}^{2+}$ and $\mathrm{CO}^{2+}$ decorated porous magnetic silica spheres synthesized by hydrothermal-assisted modified-Stober method for His-tagged proteins separation. J. Coll. Interface Sci. 2012; 365(1):156-162.

101. Borlido L, Azevedo AM, Roque AC, Aires-Barros MR. Potential of boronic acid functionalized magnetic particles in the adsorption of human antibodies under mammalian cell culture conditions. J. Chromatogr A. 2011; 1218(43):7821-7827. [PubMed: 21937050]

102. Borlido L, Azevedo AM, Sousa AG, Oliveira PH, Roque AC, Aires-Barros MR. Fishing human monoclonal antibodies from a CHO cell supernatant with boronic acid magnetic particles. J. Chromatogr. B. 2012; 903:163-170.

103. Ito A, Kamihira M. Tissue engineering using magnetite nanoparticles. Prog. Mol. Biol. Translat. Sci. 2011; 104:355-395.

104. Guillotin B, Guillemot F. Cell patterning technologies for organotypic tissue fabrication. Trends Biotechnol. 2011; 29(4):183-190. [PubMed: 21256609]

105. Sensenig R, Sapir Y, MacDonald C, Cohen S, Polyak B. Magnetic nanoparticle-based approaches to locally target therapy and enhance tissue regeneration in vivo . Nanomedicine (Lond.). 2012; 7(9):1425-1442. [PubMed: 22994959]

106. Yamamoto Y, Ito A, Kato M, et al. Preparation of artificial skeletal muscle tissues by a magnetic force-based tissue engineering technique. J. Biosci. Bioeng. 2009; 108(6):538-543. [PubMed: 19914590]

107. Whatley BR, Li X, Zhang N, Wen X. Magnetic-directed patterning of cell spheroids. J. Biomed. Mater. Res. A. 2013 Epub ahead of print.

108. Ito A, Hayashida M, Honda H, et al. Construction and harvest of multilayered keratinocyte sheets using magnetite nanoparticles and magnetic force. Tissue Eng. 2004; 10(5-6):873-880. [PubMed: 15265305]

109. Sato M, Ito A, Akiyama H, Kawabe Y, Kamihira M. Effects of B-cell lymphoma 2 gene transfer to myoblast cells on skeletal muscle tissue formation using magnetic force-based tissue engineering. Tissue Eng. Part A. 2013; 19(1-2):307-315. [PubMed: 23088454] 
110. Kim JA, Choi JH, Kim M, et al. High-throughput generation of spheroids using magnetic nanoparticles for three-dimensional cell culture. Biomaterials. 2013; 34(34):8555-8563. [PubMed: 23937911]

111. Pardridge WM. The blood-brain barrier: bottleneck in brain drug development. NeuroRx. 2005; 2(1):3-14. [PubMed: 15717053] - Provides a thorough review of the physiology of the bloodbrain barrier and the limitations it poses for CNS drug delivery. Methods to overcome these limitations are discussed.

112. Hindmarch I, Shamsi Z, Kimber S. An evaluation of the effects of high-dose fexofenadine on the central nervous system: a double-blind, placebo-controlled study in healthy volunteers. Clin. Exper. Allergy. 2002; 32(1):133-139. [PubMed: 12002730]

113. Blanchette M, Michaud K, Fortin D. A new method of quantitatively assessing the opening of the blood-brain barrier in murine animal models. J. Neurosci. Method. 2012; 207(2):125-129.

114. Pathirana W, Gunasekera SM, Constantine GR, Perera S, Perera BM, Kamaladiwela R. Brain targeted transcranial administration of diazepam and shortening of sleep latency in healthy human volunteers. Indian J. Pharmaceut. Sci. 2011; 73(5):497-503.

115. Salahuddin TS, Johansson BB, Kalimo H, Olsson Y. Structural changes in the rat brain after carotid infusions of hyperosmolar solutions. An electron microscopic study. Acta Neuropathol. 1988; 77(1):5-13. [PubMed: 3149121]

116. Cornford EM, Young D, Paxton JW, Sofia RD. Blood-brain barrier penetration of felbamate. Epilepsia. 1992; 33(5):944-954. [PubMed: 1396440]

117. Peura L, Malmioja K, Huttunen K, et al. Design, synthesis and brain uptake of LAT1-targeted amino acid prodrugs of dopamine. Pharmaceut. Res. 2013; 30(10):2523-2537.

118. Wu J, Yoon SH, Wu WM, Bodor N. Synthesis and biological evaluations of brain-targeted chemical delivery systems of [Nva2]-TRH. J. Pharm. Pharmacol. 2002; 54(7):945-950. [PubMed: 12162713]

119. Pardridge WM, Boado RJ. Reengineering biopharmaceuticals for targeted delivery across the blood- brain barrier. Methods Enzymol. 2012; 503:269-292. [PubMed: 22230573]

120. Pardridge WM. Re-engineering biopharmaceuticals for delivery to brain with molecular Trojan horses. Bioconjug. Chem. 2008; 19(7):1327-1338. [PubMed: 18547095]

121. Chen H, Tang L, Qin Y, et al. Lactoferrin-modified procationic liposomes as a novel drug carrier for brain delivery. Eur. J. Pharma. Sci. 2010; 40(2):94-102.

122. Teow HM, Zhou Z, Najlah M, Yusof SR, Abbott NJ, D'Emanuele A. Delivery of paclitaxel across cellular barriers using a dendrimer-based nanocarrier. Int. J. Pharmaceut. 2013; 441(1-2): 701-711.

123. Li J, Zhang C, Li J, et al. Brain delivery of NAP with PEG-PLGA nanoparticles modified with phage display peptides. Pharmaceut. Res. 2013; 30(7):1813-1823.

124. Jones SK, Rutherford KF, Ruys AJ, Gray BN. US patent application: microparticles for selectively targeted hyperthermia. WO 2004064921 A1(PCT/ AU2004/000089); issue date. 2006 Jul 6.

125. Zhao M, Liang C, Li A, et al. Magnetic paclitaxel nanoparticles inhibit glioma growth and improve the survival of rats bearing glioma xenografts. Anticancer Res. 2010; 30(6):2217-2223. [PubMed: 20651372]

126. Chertok B, David AE, Yang VC. Polyethyleneimine-modified iron oxide nanoparticles for brain tumor drug delivery using magnetic targeting and intra-carotid administration. Biomaterials. 2010; 31(24):6317-6324. [PubMed: 20494439]

127. Chertok B, David AE, Yang VC. Brain tumor targeting of magnetic nanoparticles for potential drug delivery: effect of administration route and magnetic field topography. J. Control. Release. 2011; 155(3):393-399. [PubMed: 21763736]

128. Chang J, Jallouli Y, Kroubi M, et al. Characterization of endocytosis of transferrin-coated PLGA nanoparticles by the blood-brain barrier. Int. J. Pharmaceut. 2009; 379(2):285-292.

129. Qiao R, Jia Q, Huwel S, et al. Receptor-mediated delivery of magnetic nanoparticles across the blood-brain barrier. ACS Nano. 2012; 6(4):3304-3310. [PubMed: 22443607]

130. Gandhi N, Saiyed ZM, Napuri J, et al. Interactive role of human immunodeficiency virus type 1 (HIV-1) clade-specific Tat protein and cocaine in blood-brain barrier dysfunction: implications 
for HIV-1-associated neurocognitive disorder. J. Neurovirol. 2010; 16(4):294-305. [PubMed: 20624003]

131. Wang H, Zhang S, Liao Z, et al. PEGlated magnetic polymeric liposome anchored with TAT for delivery of drugs across the blood-spinal cord barrier. Biomaterials. 2010; 31(25):6589-6596. [PubMed: 20553983]

132. Mejias R, Gutierrez L, Salas G, et al. Long term biotransformation and toxicity of dimercaptosuccinic acid-coated magnetic nanoparticles support their use in biomedical applications. J. Control. Release. 2013; 171(2):225-233. [PubMed: 23906866]

133. Li Y, Liu J, Zhong Y, et al. Biocompatibility of $\mathrm{Fe}_{3} \mathrm{O}_{4} @ \mathrm{Au}$ composite magnetic nanoparticles in vitro and in vivo . Int. J. Nanomed. 2011; 6:2805-2819.

134. Richards JM, Shaw CA, Lang NN, et al. In vivo mononuclear cell tracking using superparamagnetic particles of iron oxide: feasibility and safety in humans. Circ. Cardiovasc. Imag. 2012; 5(4):509-517.

135. Ahamed M, Alhadlaq HA, Alam J, Khan MA, Ali D. Alarafi S. Iron oxide nanoparticle-induced oxidative stress and genotoxicity in human skin epithelial and lung epithelial cell lines. Curr. Pharmaceut. Design. 2013; 19(37):6681-6690.

136. Ma P, Luo Q, Chen J, et al. Intraperitoneal injection of magnetic $\mathrm{Fe}_{3} \mathrm{O}_{4}$-nanoparticle induces hepatic and renal tissue injury via oxidative stress in mice. Int. J. Nanomed. 2012; 7:4809-4818.

137. Szalay B, Tatrai E, Nyiro G, Vezer T, Dura G. Potential toxic effects of iron oxide nanoparticles in in vivo and in vitro experiments. J. Appl. Toxicol. 2012; 32(6):446-453. [PubMed: 22161551] - Presents an extensive overview of the toxic potential of MNPs with an eye to optimum biological applications of biocomposite MNPs.

138. Iversen NK, Frische S, Thomsen K, et al. Superparamagnetic iron oxide polyacrylic acid coated gamma- $\mathrm{Fe}_{2} \mathrm{O}_{3}$ nanoparticles do not affect kidney function but cause acute effect on the cardiovascular function in healthy mice. Toxicol. Appl. Pharmacol. 2013; 266(2):276-288. [PubMed: 23142473]

139. Ke Y, Ming Qian Z. Iron misregulation in the brain: a primary cause of neurodegenerative disorders. Lancet Neurol. 2003; 2(4):246-253. [PubMed: 12849213]

140. Doraiswamy PM, Finefrock AE. Metals in our minds: therapeutic implications for neurodegenerative disorders. Lancet Neurol. 2004; 3(7):431-434. [PubMed: 15207800]

141. Kim JE, Shin JY, Cho MH. Magnetic nanoparticles: an update of application for drug delivery and possible toxic effects. Arch. Toxicol. 2012; 86(5):685-700. [PubMed: 22076106]

142. Chomoucka J, Drbohlavova J, Huska D, Adam V, Kizek R, Hubalek J. Magnetic nanoparticles and targeted drug delivering. Pharmacol. Res. 2010; 62(2):144-149. [PubMed: 20149874]

143. Zhang J, Shin MC, David AE, et al. Long-circulating heparin-functionalized magnetic nanoparticles for potential application as a protein drug delivery platfor. Mol. Pharmaceut. 2013; 10(10):3892-3902.

144. Lee JH, Jang JT, Choi JS, et al. Exchange-coupled magnetic nanoparticles for efficient heat induction. Nat. Nanotechnol. 2011; 6(7):418-422. [PubMed: 21706024]

145. Wahajuddin, Arora S. Superparamagnetic iron oxide nanoparticles: magnetic nanoplatforms as drug carriers. Int. J. Nanomed. 2012; 7:3445-3471.

146. Cansell F, Chevalier B, Demourgues A, et al. Supercritical fluid processing: a new route for materials synthesis. J. Mater. Chem. 1999; 9(1):67-75.

147. Kumagai M, Kano MR, Morishita Y. Enhanced magnetic resonance imaging of experimental pancreatic tumor in vivo by block copolymer-coated magnetite nanoparticles with TGF-beta inhibitor. J. Control. Release. 2009; 140(3):306-311. [PubMed: 19524625] • Significant study describing the use of MNPs for bioimaging and diagnostic applications. 


\section{Executive summary}

\section{Magnetic nanoparticle systems: translational design considerations}

- Magnetic nanoparticle (MNP)-based biocomposites are a promising theranostic platform.

- The versatility of MNP-based nanotechnology is attributed to particle response to an external magnetic field.

- Drug targeting is facilitated through functionalization of MNPs with bioactive moieties.

- Superparamagnetism of MNPs impedes particle aggregation.

\section{Challenges}

- While MNPs appears to hold significant potential, long-term evaluation is required to minimize human health risks.

- MNPs require thorough pre-evaluation for biocompatibility and biodistribution.

- MNPs should be eliminated from the body quickly once they have achieved therapeutic end points.

- The development of MNPs for therapeutic purposes is in a nascent stage.

\section{Future perspective}

- Collaborative multidisciplinary science will herald next-generation MNPs, where theranostics will ultimately be part of standard medical practices. 


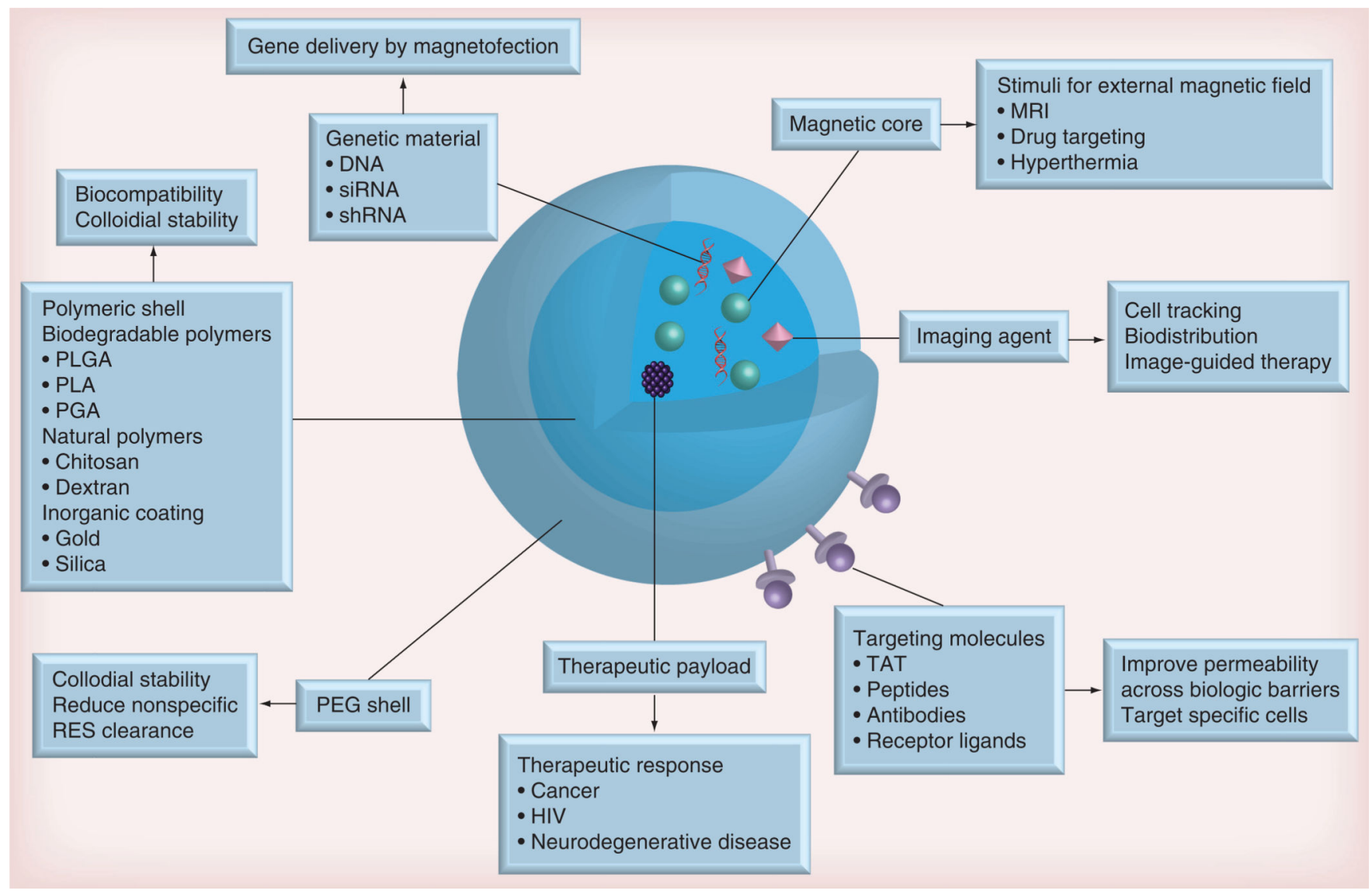

Figure 1. Basic features and biological applications of multifunctional biocomposite magnetic nanoparticles

PEG: Poly(ethylene glycol); PLA: Poly(lactic acid); PGA: Poly(glycolic acid); PLGA:

Poly(lactic-co-glycolic) acid; RES: Reticuloendothelial system. 
(A) SMART particle synthesis and characterization

(B) Parenteral injection of SMART particles in mice
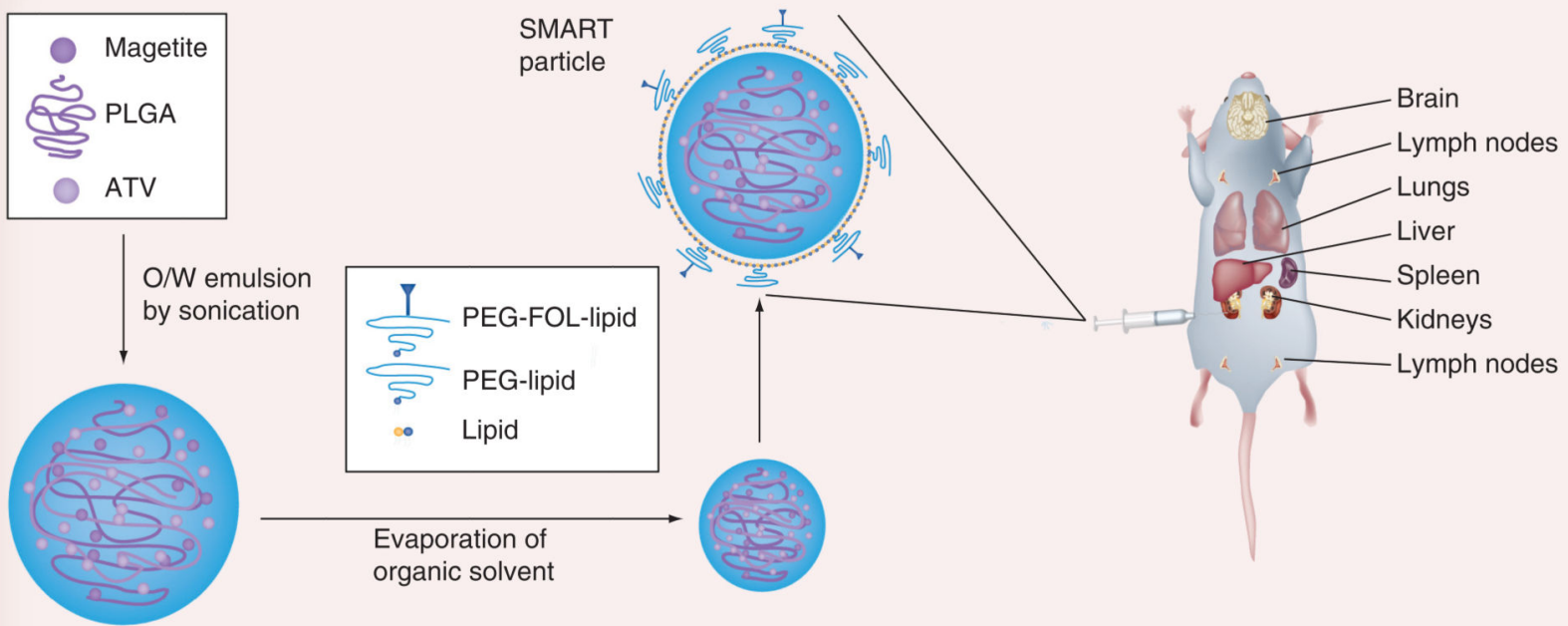

(C) Monocyte-macrophage uptake of SMART particles
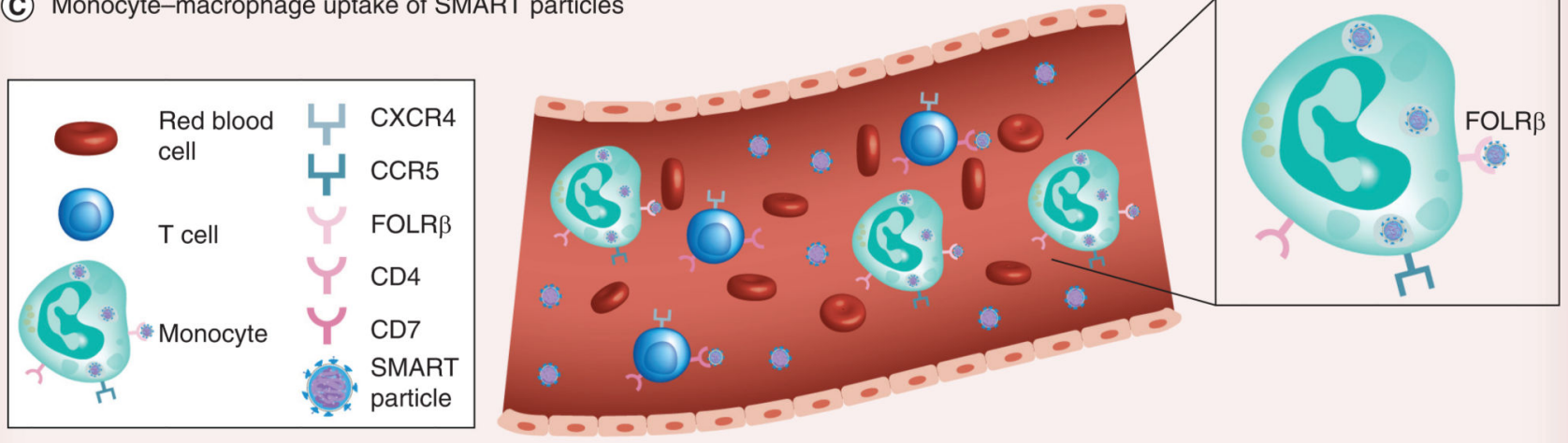

(D) MRI for SMART particle pharmacokinetics and pharmacodynamics

(c) Nanomedicine (2014)

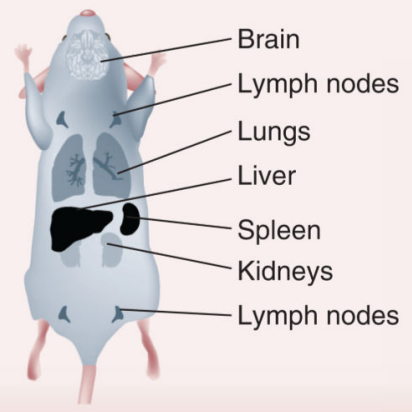

Figure 2. Small magnetitie antiretroviral particles for speeding pharmacokinetic and pharmacodynamic evaluations

(A) The composition of SMART particles is described. The particle core is comprised of magnetite and ATV distributed within a PLGA matrix. The particle core is coated with lipid, PEG-conjugated lipid (PEG-lipid) and lipid conjugated with putative targeting ligands, such as FOL-modified PEG (PEG-FOL-lipid). (B) SMART particles can be targeted to the FOLR and parentally administered to mice. (C) In blood, they are taken up by circulating monocytes or monocyte-derived macrophages. Through particle interaction with the 
FOLR $\beta$, they are trafficked into tissues reflective of active viral growth. (D)

Pharmacokinetics and pharmacodynamics of the targeted SMART particles can be monitored by MRI, where the presence of magnetite PEG-FOL-lipid-coated particles appear blackened in $\mathrm{T}_{2}$-weighted images. ATV: Atazanavir; FOL: Folate; FOLR: Folate receptor; O/W: Oil/water; PEG: Poly(ethylene glycol); PLGA: Poly(lactic-co-glycolic) acid; SMART: Small magnetite antiretroviral therapy. 

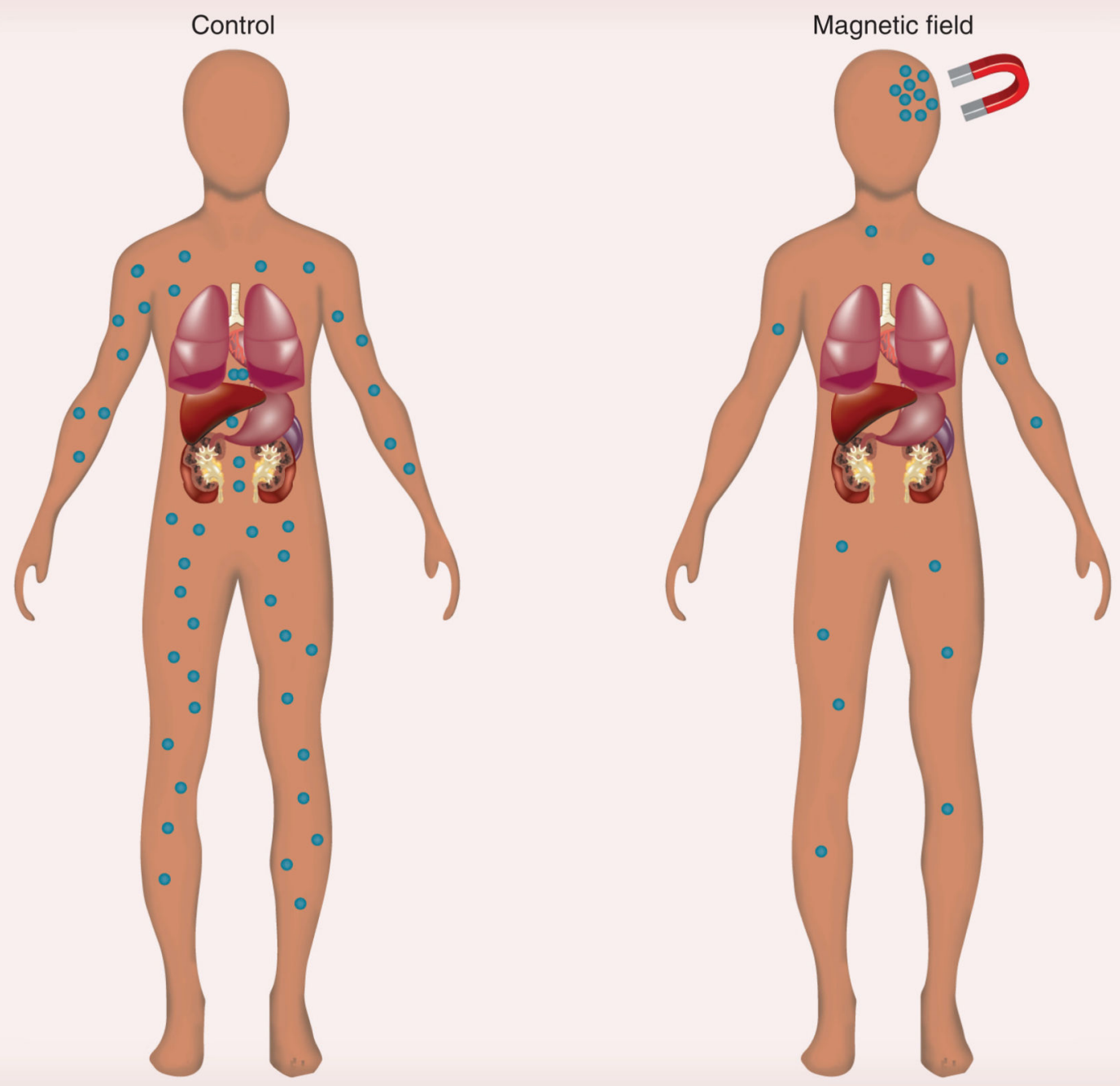

Figure 3. Magnetic targeting

No accumulation of magnetic nanoparticles (MNPs) occurs in the absence of a magnetic field, whereas under the influence of this field, MNPs alone or in combination with therapeutic cargo accumulate at a destined site. This includes the brain. Targeting efficiency of MNPs can be further improved by modifying the MNP surface using cell-specific targeting moieties, for instance, transferrin for brain targeting. 


\section{Table 1}

Magnetic nanoparticle systems in clinical use and clinical studies.

\begin{tabular}{|c|c|c|c|}
\hline Name (type) & Application & Administration & Ref. \\
\hline \multicolumn{4}{|l|}{ In clinical use } \\
\hline $\begin{array}{l}\text { Feridex }{ }^{\circledR} \text { IV (ferumoxides; Advanced Magnetic } \\
\text { Pharmaceuticals, MA, USA) }\end{array}$ & MRI of the liver and spleen & iv. & {$[11]$} \\
\hline $\begin{array}{l}\text { Endorem }{ }^{\circledR} \text { (ferumoxides; Advanced Magnetic } \\
\text { Pharmaceuticals) }\end{array}$ & $\begin{array}{l}\text { MRI of liver lesions, cardiac infarts and brain } \\
\text { lesions }\end{array}$ & iv. & {$[11]$} \\
\hline $\begin{array}{l}\text { Resovist }^{\circledR} \text { (ferucarbotran; SPIONs; Bayer Schering } \\
\text { Pharma AG, Leverkusen, Germany) }\end{array}$ & $\begin{array}{l}\text { MRI of liver lesions, cardiac infarts and brain } \\
\text { lesions }\end{array}$ & iv. & {$[11]$} \\
\hline $\begin{array}{l}\text { Lumiren }{ }^{\circledR} \text { (SPIONs; Advanced Magnetic } \\
\text { Pharmaceuticals) }\end{array}$ & MRI of the bowel & iv. & [9] \\
\hline $\begin{array}{l}\text { Combidex }{ }^{\circledR} \text { (SPIONs; Advanced Magnetic } \\
\text { Pharmaceuticals) }\end{array}$ & MRI of lymph node metastases & iv. & {$[9]$} \\
\hline \multicolumn{4}{|l|}{ Phase I clinical studies } \\
\hline $\begin{array}{l}\text { Magnetofluid MFL 082AS (SPIONs; Magforce } \\
\text { AG, Berlin, Germany) }\end{array}$ & Hyperthermia treatment of prostate tumors & Transperineally into tumor & {$[12,13]$} \\
\hline $\begin{array}{l}\text { NanoTherm }{ }^{\circledR} \text { AS1 (magnetic fluid MFL AS1; } \\
\text { SPIONs; Magforce AG) }\end{array}$ & $\begin{array}{l}\text { Hyperthermia treatment of glioblastoma } \\
\text { multiforme }\end{array}$ & Instillation into tumor & {$[14]$} \\
\hline $\begin{array}{l}\text { Ferrofluid epirubicin (Nano-Technologies GBR, } \\
\text { Berlin, Germany) }\end{array}$ & $\begin{array}{l}\text { Magnetic targeted delivery of } 4 \text { '- } \\
\text { epidoxorubicin into solid tumors }\end{array}$ & iv. & {$[15]$} \\
\hline
\end{tabular}

iv.: Intravenous; SPION: Superparamagnetic iron oxide nanoparticle. 